\title{
GEOSPATIAL ANALYSIS USING REMOTE SENSING IMAGES: CASE STUDIES OF ZONGULDAK TEST FIELD
}

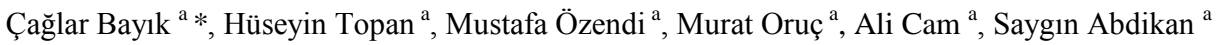 \\ ${ }^{a}$ BEU, Engineering Faculty, Department of Geomatics Engineering, 67100 Zonguldak, Turkey - (caglarbayik, topan, \\ mustafa.ozendi, sabdikan)@beun.edu.tr, orucm@hotmail.com, alicam193@gmail.com
}

Commission I, WG I/5

KEY WORDS: Zonguldak Test Site, Geospatial Applications, Image Fusion, Change Detection, Optical Images, Radar Data.

\begin{abstract}
:
Inclined topographies are one of the most challenging problems for geospatial analysis of air-borne and space-borne imageries. However, flat areas are mostly misleading to exhibit the real performance. For this reason, researchers generally require a study area which includes mountainous topography and various land cover and land use types. Zonguldak and its vicinity is a very suitable test site for performance investigation of remote sensing systems due to the fact that it contains different land use types such as dense forest, river, sea, urban area; different structures such as open pit mining operations, thermal power plant; and its mountainous structure. In this paper, we reviewed more than 120 proceeding papers and journal articles about geospatial analysis that are performed on the test field of Zonguldak and its surroundings. Geospatial analysis performed with imageries include elimination of systematic geometric errors, 2/3D georeferencing accuracy assessment, DEM and DSM generation and validation, ortho-image production, evaluation of information content, image classification, automatic feature extraction and object recognition, pansharpening, land use and land cover change analysis and deformation monitoring. In these applications many optical satellite images are used i.e. ASTER, Bilsat-1, IKONOS, IRS-1C, KOMPSAT-1, KVR-1000, Landsat-3-5-7, Orbview-3, QuickBird, Pleiades, SPOT-5, TK-350, RADARSAT-1, WorldView-1-2; as well as radar data i.e. JERS-1, Envisat ASAR, TerraSAR-X, ALOS PALSAR and SRTM. These studies are performed by Departments of Geomatics Engineering at Bülent Ecevit University, at İstanbul Technical University, at Yıldız Technical University, and Institute of Photogrammetry and GeoInformation at Leibniz University Hannover. These studies are financially supported by TÜBITAK (Turkey), the Universities, ESA, Airbus DS, ERSDAC (Japan) and Jülich Research Centre (Germany).
\end{abstract}

\section{INTRODUCTION}

Remote sensing technology was firstly introduced in the 1960's to collect intelligence from spy satellites. Since the 1970's Landsat series, which was developed by the United States, has been used for civilian satellites. Landsat-1 was that the first civilian Earth observation satellite was launched in 1972. Following years, seven satellites of Landsat series were launched also. It was actually first named Earth Resources Technology Satellite (ERTS). While data for visible and nearinfrared (VNIR) 4 bands with $60 \mathrm{~m}$ spatial resolution was obtained with Multispectral Scanner System (MSS) sensors in the 1970's, data for 7 bands with 30m spatial resolution was obtained with Thematic Mapper (TM) sensors in the 1980's. The Landsat Enhanced Thematic Mapper (ETM) was introduced with Landsat 7. Images consist of eight spectral bands with a spatial resolution of $30 \mathrm{~m}$ for Bands 1 to 7 (thermal is one of them). Band 8 (panchromatic) with a spatial resolution of 30m was added. Especially since the early 1990's, several satellite programs developed by many countries such as SPOT was developed by France, Belgium and Sweden; IRS was developed by India; TK-350 and KVR-1000 were developed by Russia; RADARSAT was developed by Canada; Bilsat, RASAT and GÖKTÜRK-2 missions were developed by Turkey. There are also private companies and organizations that provide satellite imagery, as well as governments. Quickbird (Pan: 65cm, MS: $2.62 \mathrm{~m}$ ) and WorldView-1 (Pan: 50cm, MS: $2 \mathrm{~m}$ ) are managed by Digital Globe; IKONOS (Pan: $0.41 \mathrm{~m}$, MS: $1.65 \mathrm{~m}$ ) and GeoEye-1 (Pan: 1m, MS: 4m) are managed by Space
Imaging Pleiades (Pan: 0.7m, MS: 2.8m) is a joint project being carried out under Optical and Radar Federated Earth Observation (ORFEO) between France and Italy.

The range of wavelengths commonly used for radar remote sensing covers from approximately $1 \mathrm{~cm}$ to $1 \mathrm{~m}$ in wavelength. Synthetic aperture radar (SAR) is a form of radar which is used to create images of objects. These images can be either two or three dimensional projections of the object. One of the most important SAR systems is ERS satellites. ERS-1 was launched in 1991 and it completed its lifetime in 2000. ERS-2 which acquired images in C-band was launched in 1995. ERS-2 images are used in studies such as interferometry applications, agriculture, forestry, digital elevation model generation, deformation measurements and soil moisture mapping. JERS-1 satellite was launched in 1992 and its applications focus on: geological survey, land use-land cover observation of coastal regions, environment, disaster monitoring, etc. Radarsat-1 which was launched in 1995 is Canada's first SAR mission. RADARSAT-2 is the second Earth observation satellite of RADARSAT series that was successfully launched in 2007. RADARSAT-1 and RADARSAT- 2 are used for ice monitoring and oil pollution detection. While RADARSAT-1 have only Cband and $\mathrm{HH}$ polarization data, RADARSAT-2 have dualchannel C-band and $\mathrm{HH}, \mathrm{HV}, \mathrm{VV}, \mathrm{VH}$ polarizations. ASAR (Advanced Synthetic Aperture Radar) was an active radar sensor mounted on Envisat satellite, which was launched in 2002. ASAR is a continuation of Radarsat-1. ALOS was launched in 2006 and PALSAR (Phased Array type L-band

\footnotetext{
* Corresponding author
} 
Synthetic Aperture Radar) has three imaging modes that are SpotLight (SL): 1-3m, StripMap (SM): 3-10m and ScanSAR (SS): $60-100 \mathrm{~m}$., was launched in 2007. And it is a joint mission being carried out by a public-private-partnership. TerraSAR-X acquires data in three main imaging modes: SL: $1 \mathrm{~m}, \mathrm{SM}: 3 \mathrm{~m}$ and SS: $10 \mathrm{~m}$.

Nowadays there is a huge assortment of satellite technologies recording information about the Earth. These technologies can be used for all remote sensing applications such as environment, forestry, agriculture, geology, meteorology, marine and ocean sciences.

\section{GENERATION OF GEOSPATIAL INFORMATION FROM SATELLITE IMAGES}

Equations used in photogrammetry form the basis of generation of geospatial information from satellite images. Realizing these applications with satellite images is called "space photogrammetry". The aim is basic principles of photogrammetry adapted to motion and image acquisition techniques of the satellite.

Generation of geospatial information from satellite image includes the following topics:

- Elimination of systematic geometric distortions,

- Determination of georeferencing accuracy and validation,

- DSM and DEM generation and validation,

- Ortho-image production and validation,

- Pan-sharpening and quality investigation,

- Evaluation of information content,

- Determination of the actual spatial resolution of the image,

- Automatic feature extraction and object recognition,

- Combination with imagery and geographicallyreferenced non-image data;

The researchers estimate potential of generation of geospatial information. They need numerous points with high-accuracy, uniformly distributed along vertical and horizontal planes. Additionally, they need higher quality data such as maps and ortho-images in order to validate quality of DEM, The fact of having different land cover and landforms of study area is extremely important to reveal the true geospatial potential of images.

\section{ZONGULDAK TEST FIELD AND IMAGES INVESTIGATED}

\subsection{Zonguldak Test Field}

Since 2000s, various kind of aerial and space borne remote sensed optical and microwave images are evaluated over Zonguldak (Turkey) test site. Zonguldak test field is located in Western Black Sea region of Turkey. It is famous with being one of the main coal mining areas in Turkey. The main characteristics of Zonguldak test area:
- Dense settlement on rough topography,

- Dense forest,

- Agricultural areas,

- Various water bodies such as rivers, sea, and dams,

- Open and underground mining areas,

- Thermal power stations,

- Iron and steel plants etc.

Zonguldak city centre was also constructed on this undulating mountainous topography (Figure 1).

As known, one of the most significant problems for space-borne imagery is the inclined topographies that are why fully flat areas are always misleading to exhibit the performance of proposed techniques. To demonstrate the contribution of techniques in this paper, the researcher consciously preferred a study area that includes rough terrain Zonguldak and its surroundings is a very suitable test site for the study due to different land use types and its mountainous structure.

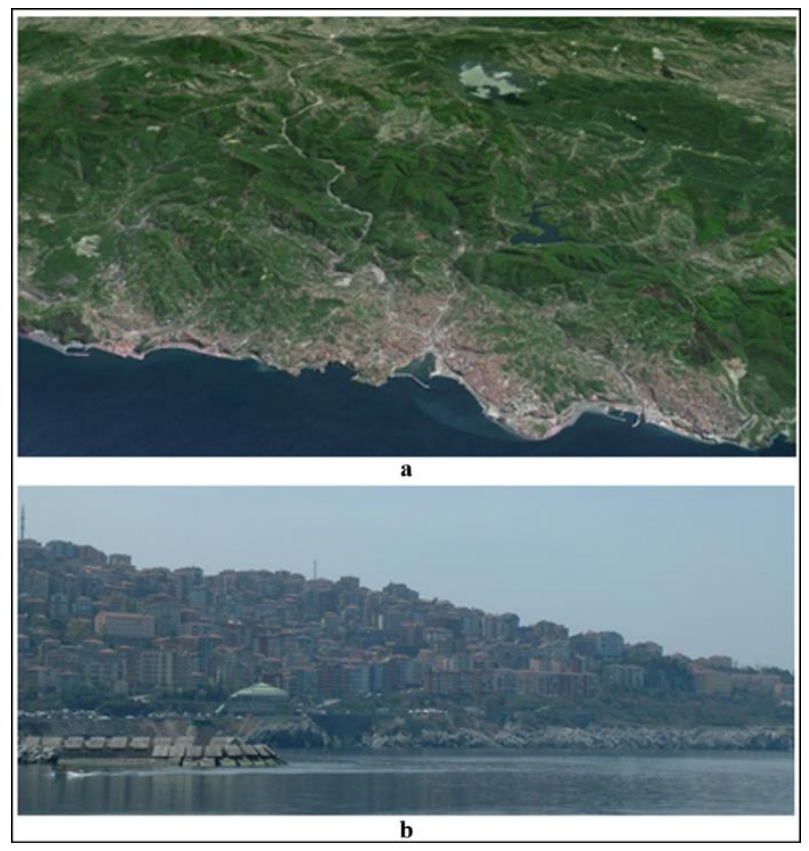

Figure 1. Zonguldak and its surrounding from Google Earth (a), and an example of Zonguldak topography (b).

\subsection{Images Investigated}

The investigated images were originated from various countries within various research projects. Figure 2 illustrates the countries with respect to the number of sensors investigated. The ESA missions were ignored since this is an international organization.

Some images such as Bilsat-1 and TK-350 were evaluated in a limited number of studies worldwide. The diversity of images provides the comprehensive comparison each other, covering such extreme topography.

- Mountainous and undulating topography, 


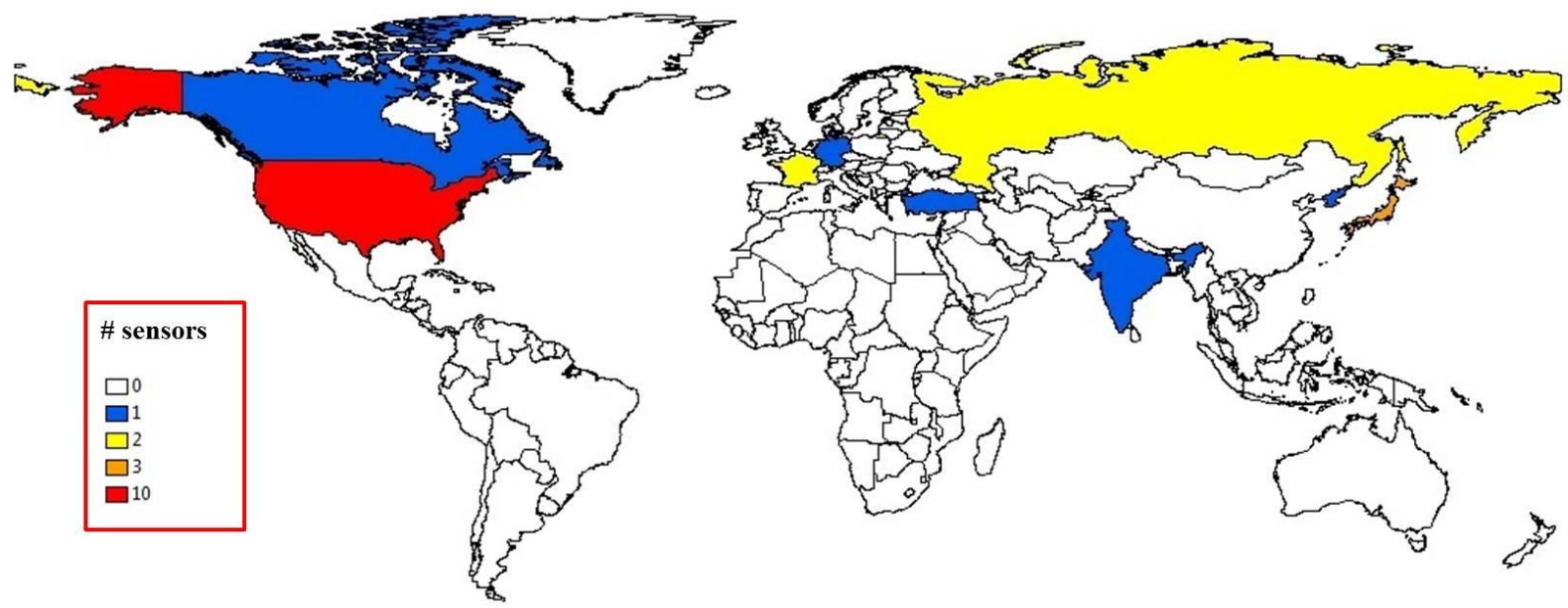

Figure 2. Developer countries of investigated sensors.

\section{GEOSPATIAL ANALYSIS}

\subsection{2/3D Georeferencing Accuracy Assessment}

Mountainous and rough areas are suitable to find out real geometric potential of optical and SAR images. Mathematical models may generate unsatisfactory results for these areas that are expected to be successful. So that, Zonguldak is an ideal test field for 2/3D georeferencing accuracy assessment. Researchers have been estimated with an accuracy of under 1 pixel for all images using the sensor dependent, sensor independent and figure condition methods, and adjustment method was preferred in these researches with ranging between 23 to 163 GCPs distributed in horizontal and vertical planes. It is certain that the accuracy may increase in the future with some developments, for example, using a collocation model which considers constraints among the parameters or different models other than the second-order polynomial for modelling the parameters can be used. TK-350, Spot-5, ASTER, Kompsat-1, KVR-1000, IRS-1C, OrbView-3, Bilsat-1, IKONOS, QuickBird and Pleiades have been investigated for 2/3D georeferencing accuracy in the Zonguldak test field (Figure 3). These studies were carried out by developing academic software BLUH system and GeoEtrim, and a commercial one, PCI Geomatica.

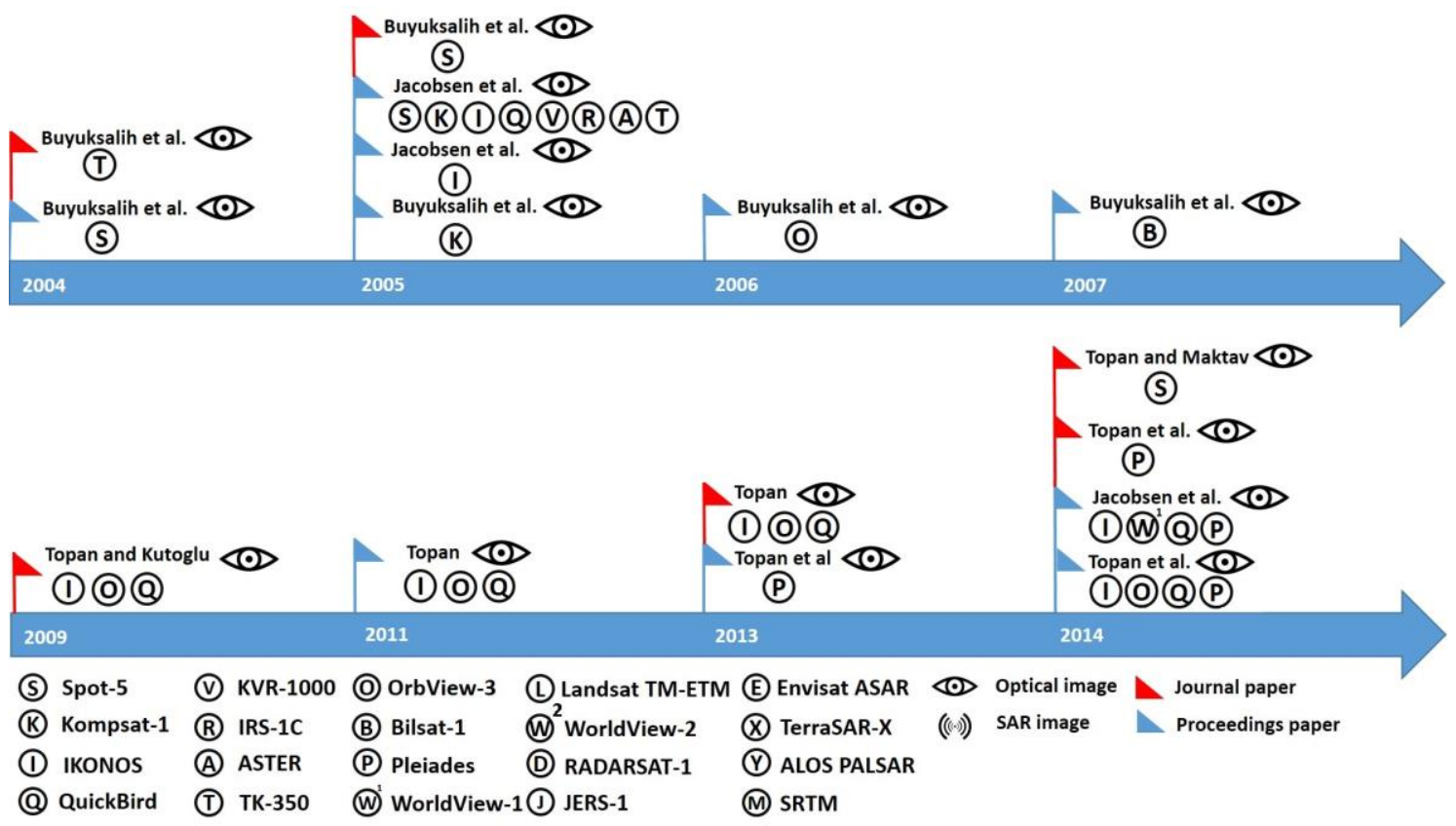

Figure 3. Summary of previous studies of 2/3D georeferencing accuracy assessment.

\subsection{DEM Generation and Validation}

Digital Elevation Model (DEM) is the simplest form of 3D representation of a terrain's surface. DEMs provide significant information for commercial and public applications such as generation of orthoimages, navigation, hydrology, disaster management, environmental analysis, contour lines generation, cartography, civil applications, geographical information system (GIS), urban planning, disaster management agriculture, land cover classification and many more. There are many techniques for DEM generation in remote sensing such as traditional photogrammetry based on aerial photos, stereo-optical satellite imagery, air-borne laser scanning (LiDAR) and interferometric synthetic aperture radar (InSAR). Other methods except LiDAR 
have been used in Zonguldak test field. By this time, many SAR and optical sensors such as TK-350, ASTER, Kompsat-1, Spot5, IKONOS, QuickBird, Pleiades, TerraSAR-X, COSMOSkyMed and SRTM have been used for DEM generation and validation in the Zonguldak test field (Figure 4). The existing DEM from the topographic map could be used, but has to be checked for changes and also correctness which is not guaranteed in case of Zonguldak test field. DEM generation studies in Zonguldak with SAR and optical images demonstrate the effectiveness of the approach covering a mountainous, rough and forest areas. Where DSMs were generated by PCI Geomatica and BLUH system, the filtering DSM to DEM and validation were carried out by BLUH system.

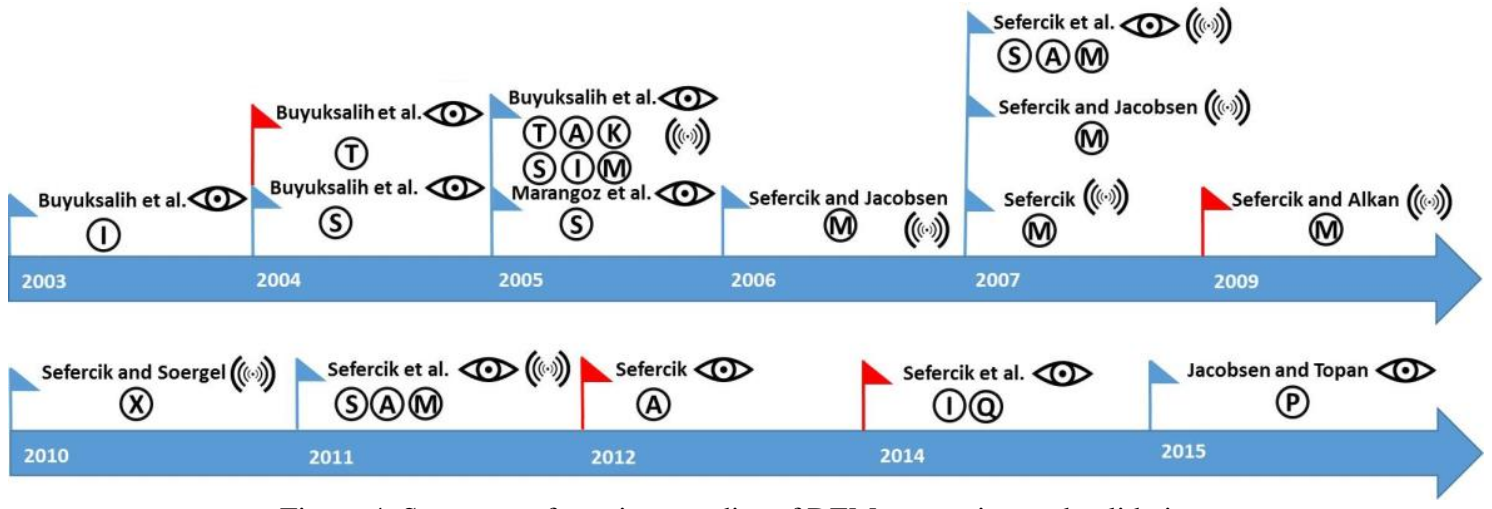

Figure 4. Summary of previous studies of DEM generation and validation.

\subsection{Information Content}

The extraction of object has become easier and more accurate with enhanced geometric resolution. The grey value range and spectral resolution are very important for recognition and classification of objects. The nominal ground sampling distance (GSD) may not be equivalent of effective GSD corresponding to the information content. Object recognition is affected by the topographic conditions, object contrast, sun elevation and azimuth and atmospheric conditions. The information content of panchromatic and multispectral satellite images (Landsat 7
ETM+, ASTER, OrbView-3，TK-350，KVR-1000，SPOT-5, IRS-1C, Kompsat-1, Bilsat-1, IKONOS, QuickBird and Pleiades) are available for the Zonguldak test field (Figure 5). As a rule of thumb, the measurement precision of visual interpretation is $0.25 \mathrm{~mm}$, and one object (i.e. an edge) can be recognized by $3 \times 3$ or $5 \times 5$ pixels. Considering these cases, the following formula can be valid for the printed maps.

$$
\text { GSD }=\left(\frac{1}{a} \sim \frac{1}{5}\right) \times 0.25 \mathrm{~mm} \times \text { scale }
$$

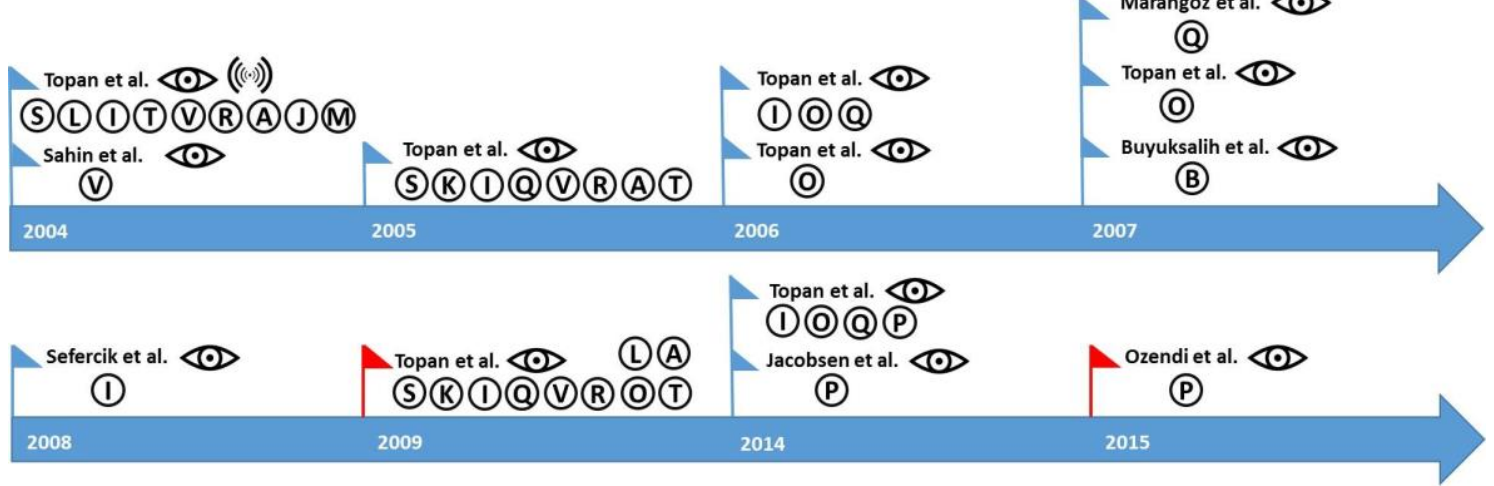

Figure 5. Summary of previous studies of information content.

\subsection{Object Recognition}

Projected pixel size and Ground Sampling Distance (GSD) are very important terms of geometric resolution. The first term is the physical size of the projected pixel, and second one refers the distance of the centres of neighboured pixels projected on the ground. The effective GSD should be determined for object extraction. Object extraction methods like manual and automatic object based image analysis (OBIA) have been widely used in order to detect temporal changes of earth surface including all terrain and non-terrain objects such as buildings, forest, and roads etc. in remote sensing applications. Manual extraction method is performed on screen manual digitizing of images. The automatic extraction method is definitely faster compared to manual extraction method and additionally facilitates the extraction of vector semantic data. Furthermore, automatic extraction data can be easily used with computer aided design (CAD) and geographic information system (GIS) based software. Objects have been recognized and extracted using eCognition. Overall accuracy of object-oriented classification of satellite data generation, such as the Landsat, SPOT, ASTER and KVR-1000 were 70\%-85\%. IKONOS, QuickBird or OrbView sensors with $1 \mathrm{~m}$ spatial resolution, overall accuracy was determined as $80 \%-90 \%$. The object recognition difficulties are decreased and overall accuracy is increased with commercial satellites with resolution of $\mathrm{cm}$ (Worldview, GeoEye) in the late 2000's (Figure 6). 


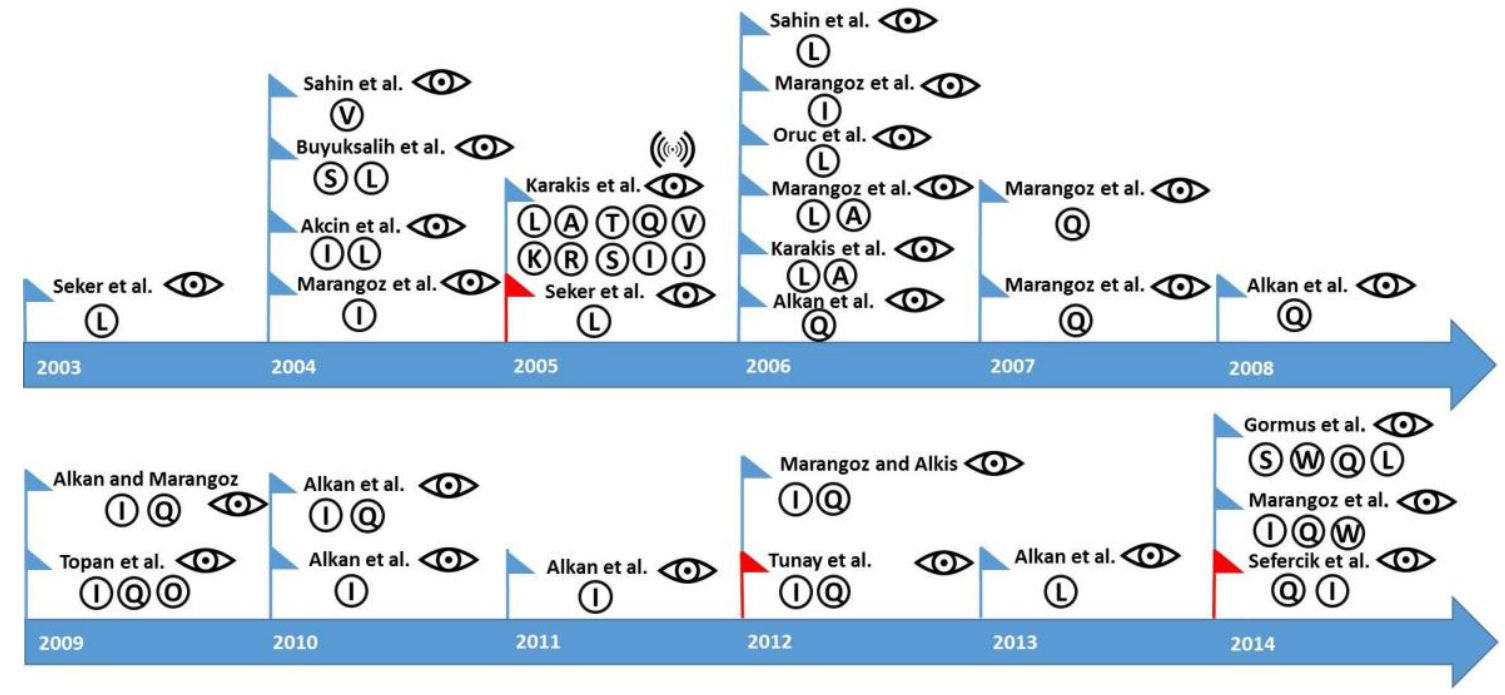

Figure 6. Summary of previous studies of object recognition.

\subsection{Deformation Monitoring}

In these studies, researchers reported the results of long time subsidence monitoring by persistent scatterer interferometry (PSI) analysis with C- and L-band SAR data and GPS measurements over the coal mines, Kozlu, Uzulmez and Karadon. In order to determine deformation of deep forest area, L-band is necessary so researchers use ALOS PALSAR and JERS-1 for periodic observations. The applications of InSAR technique using C-band microwave such as TerraSAR-X, ENVISAT ASAR and RADARSAT- 1 have been reported in the determination of subsidence in the urban area. In first studies, deformation was detected by PALSAR approximately 3-4 $\mathrm{cm} / 46$ days in 2006. On the other hand, deformation was generally rated as $20-40 \mathrm{~mm} / \mathrm{year}$ in same study area using ALOS PALSAR data (Figure 7). Studies were performed by various commercial and academic softwares.
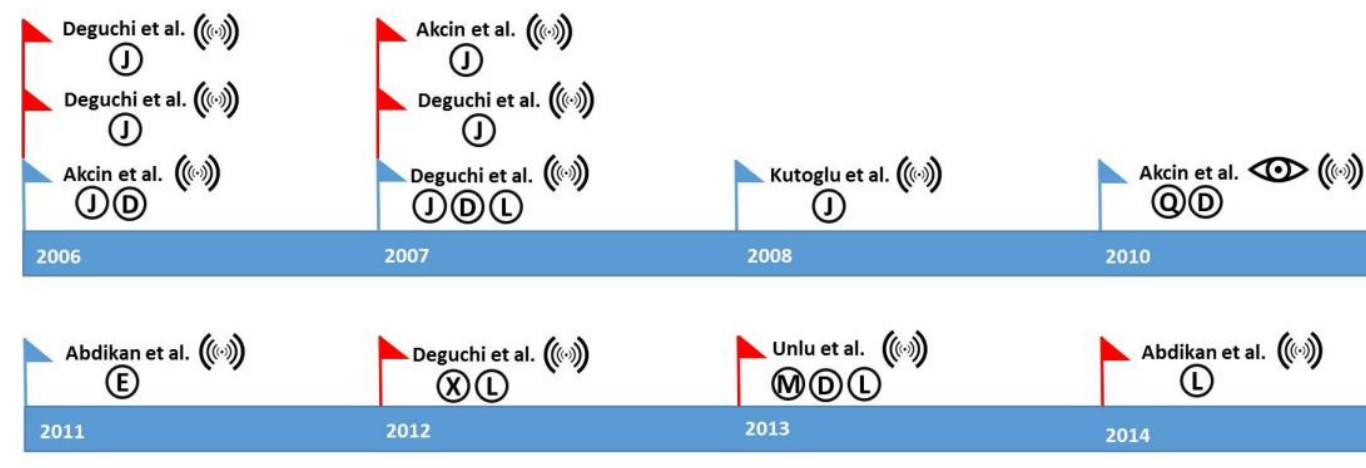

¿eguchi et al. ((*)))

Figure 7.

Figure 7. Summary of previous studies of deformation monitoring.

\section{CONCLUSION}

Combination of mountain and forest areas is complex problem and must be used several algorithms for geospatial analysis. However, the results obtained in flat areas are not satisfactory. Accordingly, researchers prefer area that has mountainous topography and different land use types as like Zonguldak test field. Zonguldak have many different natural land use types such as dense forest, river, sea, urban area and different nonnatural structures such as open pit mining operations, thermal power plant. Because of this fact, Zonguldak and its surrounding is suitable to find out real geometric potential of SAR and optical images. In this paper, more than 60 proceeding papers and more than 20 journal papers about geospatial analysis applications that are performed on the test field of Zonguldak and its surroundings were reviewed. In mentioned papers, many geospatial analysis in Zonguldak test field were reviewed by authors. These applications include elimination of systematic geometric errors, 2/3D georeferencing accuracy assessment, DSM and DEM generation and validation, orthoimage production, evaluation of information content, image classification, automatic feature extraction and object recognition, pan-sharpening, land use and land cover change analysis and deformation monitoring. The geospatial analysis applications of panchromatic and multispectral satellite images such as ASTER, Bilsat-1, IKONOS, IRS-1C, KOMPSAT-1, KVR-1000, Landsat-3-5-7, Orbview-3, QuickBird, Pleiades, SPOT-5, TK-350, RADARSAT-1, WorldView-1-2 and radar image such as JERS-1, Envisat ASAR, TerraSAR-X, ALOS PALSAR and SRTM are used for the Zonguldak test field. Geomatics Engineering Departments of Bülent Ecevit University, İstanbul Technical University, Yıldız Technical University, and Institute of Photogrammetry and GeoInformation at Leibniz University Hannover achieved success in their applications. TÜBITAK (Turkey), the Universities, ESA, Airbus DS, ERSDAC (Japan) and Jülich 
Research Centre (Germany) supported these researches. These studies with various scopes make Zonguldak a significant test field.

\section{REFERENCES}

Abdikan, S., Arıkan, M., Sanli, F.B., Cakir, Z., 2014. Monitoring of coal mining subsidence in peri-urban area of Zonguldak city (NW Turkey) with persistent scatterer interferometry using ALOS-PALSAR. Environmental Earth Sciences, 71, 4081-4089.

Abdikan, S., Hooper, A., Arikan, M., Balik Şanli, F., Çakir, Z., Kemaldere, H., 2011. "InSAR time series analysis of coal mining in Zonguldak city, Northwestern Turkey", Fringe Workshop 2011, European Space Agency (Special Publication) SP-696, Frascati, Italy, 19-23 September 2011

Akcin, H., Degucci, T., Kutoglu, H., 2006. "Monitoring Mining Induced Subsidences Using GPS and InSAR", Proceedings of 23rd FIG Congress, October 8-13. Munich, pp. 1-12.

Akcin, H., Karakis, S., Buyuksalih, G., Oruç, M., 2004. “GIS based analysis of landcover changes arising from coal production wastes in Zonguldak Metropolitan area-Turkey", ISPRS, Istanbul, 12-23 July 2004.

Akcin, H., Kutoglu, H., Deguchi, T., Koksal, E., 2010. Monitoring subsidence effects in the urban area of Zonguldak Hardcoal Basin of Turkey by InSAR-GIS integration. Natural Hazards and Earth System Sciences, 10, 1807.

Akcin, H., Kutoglu, S., Degucci, T., 2007. Integrating GPS and SAR: Monitoring Coal-field Subsidence. GIM Internatıonal, $21,41$.

Alkan, M., Arca, D., Bayik, C., Marangoz, A., 2011. "Updating Object for GIS Database Information Using High Resolution Satellite Images: a Case Study Zonguldak", ISPRSInternational Archives of the Photogrammetry, Remote Sensing and Spatial Information Sciences, 3819, 1-6.

Alkan, M., Marangoz, A.M., 2009. "Creating cadastral maps in rural and urban areas of using high resolution satellite imagery", Applied Geo-informatics for Society and Environment-Stuttgart University of Applied Sciences.

Alkan, M., Marangoz, A.M., Karakis, S., Buyuksalih, G., 2006. "Verification of automatic and manual road extraction methods using Quickbird imagery". ISPRS Archives, 36, 4.

Alkan, M., Oruc, M., Kayabaşı, D., Sefercik, U.G., 2010. "Spatial and Temporal GIS Analysis of Change Detection Using Ikonos Images: a Case Study of Zonguldak", ISPRS Istanbul Workshop 2010 on Modeling of optical airborne and spaceborne Sensors, WG I/4, Oct. 11-13, IAPRS Vol. XXXVIII-1/W17.

Alkan, M., Oruc, M., Yildirim, Y., Seker, D., Jacobsen, K., 2013. Monitoring Spatial and Temporal Land Use/Cover Changes; a Case Study in Western Black Sea Region of Turkey. Journal of the Indian Society of Remote Sensing, 41, 587-596.

Alkan, M., Sefercik, U.G., Marangoz, A.M., Karakış, S., 2010. "Updating object for topographic map information using high resolution satellite images of Zonguldak Test field", 30th Annual Symposium of Earsel, pp. 683-690.

Alkan, M., Sefercik, U.G., Oruc, M., 2008. "Integration of High Resolution Quickbird Images to Google Earth", The International Archives of the Photogrammetry, Remote Sensing and Spatial Information Sciences. Vol. XXXVII. Part B2. Beijing 2008, 727-732.

Buyuksalih, G., Akcin, H., Jacobsen, K., 2006. "Geometry of OrbView-3 images", Proc. ISPRS Topographic Mapping Space-(With Special Emphasis on Small Satellites), 2006.

Buyuksalih, G., Akcin, H., Marangoz, A., Jacobsen, K., 2005. "Potential of KOMPSAT-1 for mapping purposes", EARSeL symposium, Porto.

Buyuksalih, G., Kocak, M., Oruc, M., Akcin, H., Jacobsen, K., 2003. "Handling of IKONOS-images from Orientation up to DEM Generation", Joint Workshop "High Resolution Mapping from Space".

Buyuksalih, G., Kocak, G., Oruc, M., Akcin, H., Jacobsen, K., 2004. Accuracy analysis, DEM generation and validation using russian tk-350 stereo-images, The Photogrammetric Record, 19, 200-218.

Buyuksalih, G., Kocak, G., Topan, H., Oruc, M., Marangoz, A., 2005. SPOT revisited: accuracy assessment, DEM generation and validation from stereo SPOT 5 HRG images. The Photogrammetric Record, 20, 130-146.

Buyuksalih, G., Marangoz, A.M., Jacobsen, K., 2005. "Generation and analysis of height models based on satellite information", Zonguldak Karaelmas University/University of Hannover.

Buyuksalih, I., Oncu, S., Akcin, H., 2004b. "Investigation of Time-Dependent Changes of Filyos River and its Delta in the Black Sea Coastal Zone by Temporal GIS”. 171-177.

Buyuksalih, G., Oruc, M., Jacobsen, K., 2007. "Investigation of BILSAT-1 imagery, in: Gomarsca”, M.A. (Ed.), Geoinformation in Europe. Millpress, Bolzano, Italy.

Buyuksalih, G., Oruc, M., Topan, H., Jacobsen, K., 2004. "Geometric Accuracy Evaluation, DEM Generation and Validation for SPOT-5 Level 1B Stereo Scene", EARSeL Workshop "Remote Sensing for Developing Countries", Cairo

Deguchi, T., Kato, M., Akcin, H., 2007. "Monitoring of mining induced land subsidence using L-and C-band SAR interferometry", 2007 IEEE International Geoscience and Remote Sensing Symposium, pp. 2122-2125.

Deguchi, T., Kato, M., Akcin, H., Kutoglu, H.S., 2006. Automatic processing of Interferometric SAR and accuracy of surface deformation measurement, Remote Sensing. International Society for Optics and Photonics, pp. 636309636309-636308.

Deguchi, T., Kato, M., Akcin, H., Kutoglu, H., 2007. "Monitoring of mining induced land deformation by interferometry using L-and C-band SAR Data", ISPRS Commission VII WG2 \& WG7 conference on information 
extraction from SAR and optical data, with emphasis on developing countries. Citeseer, pp. 16-18.

Deguchi, T., Kutoglu, H., 2012. Monitoring of mining-induced land subsidence by PALSAR and TerraSAR-X, SPIE Remote Sensing. International Society for Optics and Photonics, pp. 853611-853611-853617.

Deguchi, T., Maruyama, Y., Kato, M., Akcin, H., 2006. Application of L-band InSAR for measurement of local surface deformation by underground coal mining. Journal of Remote Sensing Society of Japan, 26, 391-398.

Gormus, K.S., Marangoz, A.M., Oruc, M., Şekertekin, A., 2014. "Temporal analysis and environmental effects of ash dam construction of Çatalağzı thermoelectric power plant (ÇATES)", South-Estern European Journal of Earth Observation and Geomatics, Vo3, No2S.

Jacobsen, K., Buyuksalih, G., Marangoz, A.M., Sefercik, U.G., Buyuksalih, I., 2005. "Geometric conditions of space imagery for mapping", Recent Advances in Space Technologies, 2005. RAST 2005. Proceedings of 2nd International Conference on. IEEE, pp. 511-516.

Jacobsen, K., Buyuksalih, G., Topan, H., 2005. "Geometric models for the orientation of high resolution optical satellite sensors", International Archives of the Photogrammetry, Remote Sensing and Spatial Information Sciences, 36, 1.

Jacobsen, K., Topan, H., 2015. "DEM Generation with Short Base Length Pleiades Triplet", ISPRS-International Archives of the Photogrammetry, Remote Sensing and Spatial Information Sciences, 1, 81-86.

Jacobsen, K., Topan, H., Cam, A., Ozendi, M., Oruc, M., 2014. "Radiometric and geometric characteristics of Pleiades images", The International Archives of Photogrammetry, Remote Sensing and Spatial Information Sciences XL.1: 173-177. Gottingen: Copernicus GmbH.

Karakis, S., Marangoz, A.M., Buyuksalih, G., 2006. “Analysis of Segmentation Parameters in Ecognition Software Using High Resolution Quickbird MS Imagery", ISPRS Workshop on Topographic Mapping from Space, Ankara.

Karakis, S., Topan, H., Buyuksalih, G., Marangoz, A.M., Jacobsen, K., 2005. "Semantic Analysis of Space Imagery for Mapping Purposes", 2nd RAST Congress, İstanbul.

Kutoglu, H., Akcin, H., Deguchi, T., Kemaldere, H., 2008. "Detecting Illegal Mining Activities Using DInSAR". Integrating Generations FIG Working Week, 14-19.

Marangoz, A.M., Alkis, Z., 2012. "Detection of Urban Details and Map Updating from Satellite Images Using Object-Based Image Classification Methods and Integration to GIS, 4th GEograhic Object-Based Image Analysis ConferenceGEOBIA", pp. 07-09.

Marangoz, A.M., Alkis, Z., Karakis, S., 2007. "Evaluation of information content and feature extraction capability of very high resolution pan-sharpened QuickBird image", Conference on Information Extraction from SAR and Optical Data, with emphasis on Developing Countries, pp. 16-18.
Marangoz, A.M., Buyuksalih, G., Buyuksalih, I., Sefercik, U., Akcin, H., 2005. "Geometric evaluation, automated DEM and orthoimage generation from along-track stereo ASTER images", Recent Advances in Space Technologies, 2005. RAST 2005. Proceedings of 2nd International Conference on. IEEE, pp. 505510.

Marangoz, A.M., Karakis, S., Akcin, H., 2007. "Object-based automatic classification of urban open green areas using high resolution QuickBird imagery and integration to GIS", 27th EARSeL Symposium on Geoinformation in Europe, EURAC Research, Bolzano, Italy, pp. 04-07.

Marangoz, A.M., Karakis, S., Oruc, M., 2006. "Analysis of Object-Oriented Classification Results Derived From Pansharpened LANDSAT 7 ETM+ and ASTER Images", ASPRS, Ankara workshop, pp. 47-50.

Marangoz, M.A., Karakis, S., Oruc, M., Sahin, H., Sefercik, U.G., Topan, H., Buyuksalih, G., 2006. "3D Cultural Heritage Documentation of Safranbolu Test Site Using High Resolution Satellite Imagery", EARSeL SIG Urban Remote Sensing.

Marangoz, A.M., Oruc, M., Buyuksalih, G., 2004. "ObjectOriented Image Analysis and Semantic Network for Extracting the Roads and Buildings from Ikonos Pan-Sharpened Images", Proceedings of the 20th ISPRS Congress, Istanbul, Turkey.

Marangoz, A.M., Oruc, M., Sekertekin, A., Gormus, K.S., 2014. "Investigation of temporal changes of Urban objects using Object-based image analysis", South-Eastern European Journal of Earth Observation and Geomatics, Vo3, No2S.

Oruc, M., Marangoz, A.M., Buyuksalih, G., 2006. "Comparison of Pixel-Based and Object-Oriented Classification Approaches Using Landsat-7 ETM Spectral Bands", Paper presented at the conference of the ISPRS. Istanbul, Turkey.

Ozendi, M., Topan, H., Oruc, M., Cam, A., 2015. Pansharpening quality investigation of PLÉIADES-1A images. Geocarto International, 1-10.

Sahin, H., Buyuksalih, G., Akcin, H., Topan, H., Karakis, S., Marangoz, A.M., 2004. "Information Content Analysis of KVR-1000 Ortho-Image Based On The Available Topographic Maps In The GIS Environment", EARSEL Workshop on Remote Sensing for Developing Countries, Cairo.

Sahin, H., Oruç, M., Buyuksalih, G., 2006. "Temporal Analysis of Multi Epoch Landsat Geocover Images in Zonguldak Testfield", ISPRS Ankara Workshop.

Sahin, H., Topan, H., Karakis, S., Marangoz, A.M., 2004. "Comparison of object oriented image analysis and manual digitizing for feature extraction", Proceedings of the ISRPS 2004 annual conference, Istanbul, Turkey. July, pp. 19-23.

Sefercik, U.G., 2007. "Comparison of DEM accuracies generated by various methods", Recent Advances in Space Technologies, 2007. RAST'07. 3rd International Conference on. IEEE, pp. 379-382.

Sefercik, U.G., 2012. Performance estimation of ASTER global DEM depending upon the terrain inclination. Journal of the Indian Society of Remote Sensing, 40, 565-576. 
Sefercik, U.G., Alkan, M., 2009. Advanced analysis of differences between $\mathrm{C}$ and $\mathrm{X}$ bands using SRTM data for mountainous topography. Journal of the Indian Society of Remote Sensing, 37, 335-349.

Sefercik, U.G., Bayik, C., Karakis, S., Jacobsen, K., 2011. "Morphologic quality of DSMs based on optical and radar space imagery", ISPRS Hannover Workshop, Hannover, Germany.

Sefercik, U., Jacobsen, K., 2006. "Analysis of SRTM height models". Turkish-German Geodetic Days, Berlin.

Sefercik, U.G., Jacobsen, K., 2007. "Quality assessment of INSAR digital elevation models", 27th EARSeL Symposium: Geoinformation in Europe, Bolzano, pp. 4-7.

Sefercik, U.G., Jacobsen, K., Oruc, M., Marangoz, A.M., 2007. "Comparison of SPOT, SRTM, and ASTER DEMs", Proc. International Society of Photogrammetry and Remote Sensing 36, W51.

Sefercik, U.G., Karakis, S., Bayik, C., Alkan, M., Yastikli, N., 2014. Contribution of Normalized DSM to Automatic Building Extraction from HR Mono Optical Satellite Imagery. European Journal of Remote Sensing, 47, 575-591.

Sefercik, U.G., Oruc, M., Alkan, M., 2008. "Adaptation of high resolution IKONOS images to Google Earth for Zonguldak test field", FIG Annual Conference.

Sefercik, U.G., Soergel, U., 2010. "Evaluation of DEMs derived by TerraSAR-X InSAR data”, Earsel symposium remote sensing for science, education, and natural and cultural heritage, Paris, France.

Seker, D.Z., Kaya, S., Musaoglu, N., Kabdasli, S., Yuasa, A., Duran, Z., 2005. Investigation of meandering in Filyos River by means of satellite sensor data. Hydrological Processes, 19, 1497-1508.

Seker, D.Z., Kaya, S., Musaoglu, N., Tanik, A., Kabdasli, S.A., Unal, E., 2003. "Remote Sensing Aided Quantitative Analys is Freshwater Flume of Filyos River in the Black Sea".

Topan, H., 2011. "GeoEtrim: Geospatial evaluation and training of images", Recent Advances in Space Technologies (RAST), 2011 5th International Conference on. IEEE, pp. 142-147.

Topan, H., 2013. First experience with figure condition analysis aided bias compensated rational function model for georeferencing of high resolution satellite images. Journal of the Indian Society of Remote Sensing, 41, 807-818.

Topan, H., Buyuksalih, G., Jacobsen, K., 2004. "Comparison of information contents of high resolution space images", International Archives of Photogrammetry, Remote Sensing and Spatial Information Sciences, 35(B4): 583-588.

Topan, H., Buyuksalih, G., Jacobsen, K., 2005. "Information contents of high resolution satellite images", EARSel 3DRemote Sensing Workshop, Porto.

Topan, H., Buyuksalih, G., Jacobsen, K., 2006. "Information contents of OrbView-3 for topographic mapping", ISPRS Ankara Workshop 2006 Topographic Mapping from Space (with Special Emphasis on Small Satellite), Ankara, 14-16 February.

Topan, H., Buyuksalih, G., Maktav, D., 2007. "Mapping Potential of Orbview-3 Panchromatic Image in Mountainous Urban Areas: Results of Zonguldak Test-Field”, Urban Remote Sensing Joint Event, 2007. IEEE, pp. 1-6.

Topan, H., Kutoglu, H.S., 2009. Georeferencing accuracy assessment of high-resolution satellite images using figure condition method. IEEE Transactions on Geoscience and Remote Sensing, 47, 1256-1261.

Topan, H., Maktav, D., 2014. Efficiency of orientation parameters on georeferencing accuracy of SPOT-5 HRG level1A stereoimages. IEEE Transactions on Geoscience and Remote Sensing, 52, 3683-3694.

Topan, H., Maktav, D., Jacobsen, K., Buyuksalih, G., 2006. "Mapping Potential of High Resolution Space Images in Mountainous Urban Areas", ISPRS International Archives of Photogrammetry and Remote Sensing, Vol. 35, Part 8, Remote Sensing Applications for a Sustainable Future, Haifa (Israel), 13 September.

Topan, H., Maktav, D., Jacobsen, K., Buyuksalih, G., 2009. Information content of optical satellite images for topographic mapping. International Journal of Remote Sensing, 30, 18191827.

Topan, H., Oruc, M., Jacobsen, K., 2009. "Potential of manual and automatic feature extraction from high resolution space images in mountainous urban areas", ISPRS Hannover Workshop.

Topan, H., Oruc, M., Taskanat, T., Cam, A., 2014. Combined Efficiency of RPC and DEM Accuracy on Georeferencing Accuracy of Orthoimage: Case Study With Pléiades Panchromatic Mono Image. Geoscience and Remote Sensing Letters, IEEE 11, 1148-1152.

Topan, H., Ozendi, M., Cam, A., Oruç, M., 2014. “GeoETRIM, SharpQ And EPIX: Trio of Tools for Geospatial Image Analysis". ISPRS-International Archives of the Photogrammetry, Remote Sensing and Spatial Information Sciences 1, 189-194.

Topan, H., Taskanat, T., Cam, A., 2013. "Georeferencing accuracy assessment of Pléiades 1A images using rational function model", International Archives of the Photogrammetry, Remote Sensing and Spatial Information Sciences, Volume XL7/W2, ISPRS2013-SSG, pages: 251-256, 11 - 17 November.

Tunay, M., Marangoz, A.M., Atesoglu, A., Akçin, H., Karakıs, S., 2012. Sustainability in Urban Ecosystems and Detecting Urban Vegetation from Different Images Using an ObjectBased Approach. Sustainable Development - Education, Business and Management - Architecture and Building Construction - Agriculture and Food Security, Editor: Dr. Chaouki Ghenai, ISBN: 978-953-51-0116-1.

Unlu, T., Akcin, H., Yilmaz, O., 2013. An integrated approach for the prediction of subsidence for coal mining basins. Engineering Geology, 166, 186-203. 